\title{
EGU21-6276
}

https://doi.org/10.5194/egusphere-egu21-6276

EGU General Assembly 2021

(c) Author(s) 2021. This work is distributed under

the Creative Commons Attribution 4.0 License.

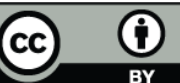

\section{The variability of river dune shape at high and low flows in a navigable river}

\author{
Lieke Lokin ${ }^{1,2}$, Jord Warmink ${ }^{1}$, Anouk Bomers ${ }^{1}$, and Suzanne Hulscher ${ }^{1}$ \\ ${ }^{1}$ University of Twente, Faculty of Engineering Technology, Department of Water Engineering and Management, Netherlands \\ (l.r.lokin@utwente.nl) \\ ${ }^{2} \mathrm{HKV}$ Consultants, Netherlands
}

During low flows, river dunes determine the navigable depth of rivers, influencing the maximum draft of ships. Accurate predictions of the height and location of river dunes during low flows is needed to plan shipping operations in rivers. Currently, little data of dune evolution during low flows is available and analyzed, as most research is focused on high flows and most data is retrieved in flume experiments. However, the scaling from flume to full scale river gives issues with the lee slope angle and secondary bed forms.[LL(1] Therefore, research on dune evolution on full scale rivers is lacking.

For this research multibeam echo sounding (MBES) measurements of the Waal river, Netherlands, were used. These measurements were done once per two weeks and cover the fairway. The data was made available by Rijkswaterstaat (Department of public works and water management, Netherlands). We developed a method to analyze dune shape in a large dataset of bed data. This method was applied on a stretch of $2 \mathrm{~km}$ Waal river, between the cities of Tiel and St. Andries. The research period covers the whole year 2018. This year is characterized by three separate discharge regimes. High water during January until March, median discharge from April until June and extreme low discharges from July until November.

In the first step of the data analysis locations of the primary dunes were determined using a wavelet analysis. At these locations, the dune crests and troughs were identified. With the crests and troughs, the shape characteristics such as dune length, height lee slope angle and propagation speed were determined. The dune characteristics were eventually related to the governing discharge.

The first results show that the river dunes are mobile during extreme low flows. After a transition period of one month, where the discharge drops from the median value towards the low discharge, the dune length and height become statistically stable. While the dune shape in flow direction becomes stable during these low flows the three dimensionality increases, not only in primary dune shape but also the appearance of secondary dunes and ripples. The dune height near the right bank is smaller than in the middle of the river, towards the left bank the height decreases again. The differences between the banks and the middle of the fairway increase as discharge decreases. Also, by visually inspecting the bed profiles at other locations, a similar trend 


\section{is observed.}

The first results show that the location in the river cross-section influences the dune characteristics. These differences increase as the discharge decreases. In further work we will extend the research area over the full length of the Waal river, to give a quantitative analysis supporting our visual results and to include influence of sediment size. As the differences in the cross-section can be found throughout the river, we will also investigate the influence of shipping on the differences in dune shape. 